\title{
USING ECOGNITION TO AUTOMATICALLY DETECT AND MAP AVALANCHE DEPOSITS FROM THE SPRING 2009 AVALANCHE CYCLE IN THE TATRA MTS., SLOVAKIA
}

\author{
R. Frauenfelder a, *, M. J. Lato ${ }^{b}$, M. Biskupič c,d \\ a Norwegian Geotechnical Institute, P.O. Box 3930 Ullevaal Stadion, 0806 Oslo, Norway - Regula.Frauenfelder@ngi.no \\ ${ }^{\mathrm{b}}$ BGC Engineering Inc., Ottawa ON, Canada - mlato@ bgcengineering.ca \\ ${ }^{c}$ Avalanche Prevention Center, Dr. J. Gašperíka 598, 03301 Liptovský Hrádok, Slovakia - avalanches@ @zs.sk \\ ${ }^{\mathrm{d}}$ Institute for Environmental Studies, Charles University, Ovocný trh 3-5, 11636 Praha 1, Czech Republic
}

KEY WORDS: Avalanche debris detection, Tatra Mountains, Slovakia, eCognition

\section{ABSTRACT:}

Here we present results from ongoing work where we apply an object oriented mapping algorithm developed in eCognition in order to automatically identify and digitally map avalanche deposits. The algorithm performance is compared with respect to a selected number of manually digitized avalanche outlines mapped by avalanche experts.

\section{INTRODUCTION}

\subsection{The March 2009 avalanche cycle in the High Tatras}

The Tatra Mountains, located in the border region between Slovakia and Poland, experienced several severe avalanche cycles during spring 2009. The peak was reached between March 25-31, 2009, when an estimated number of more than 200 avalanches were observed in the area of the Tatra national park on an area of approximately $738 \mathrm{~km}^{2}$.

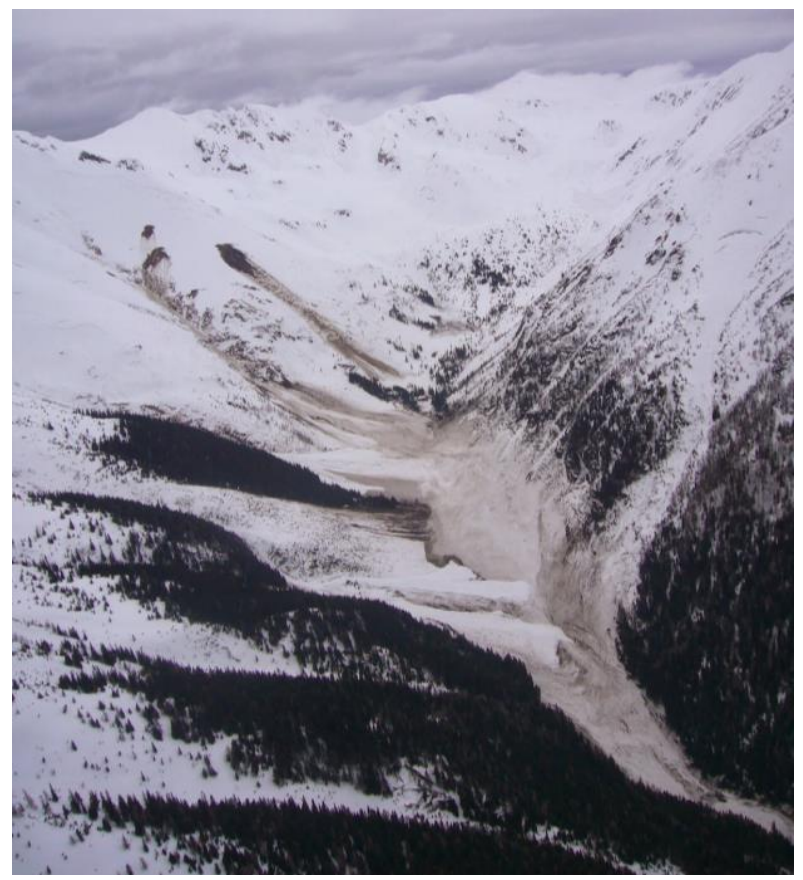

Figure 1: Avalanches in the Žiarska valley, photograph taken on April 1, 2009. Source: http://hzsslp.blogspot.sk/2014/03/5rokov-od-padu-storocnej-laviny-v.html?q=2009
Avalanches were observed in almost every gully and on many slopes. They ranged in size from small to large (cf. Figure 1,2), with the largest ones having a return period of approximately 100 year.

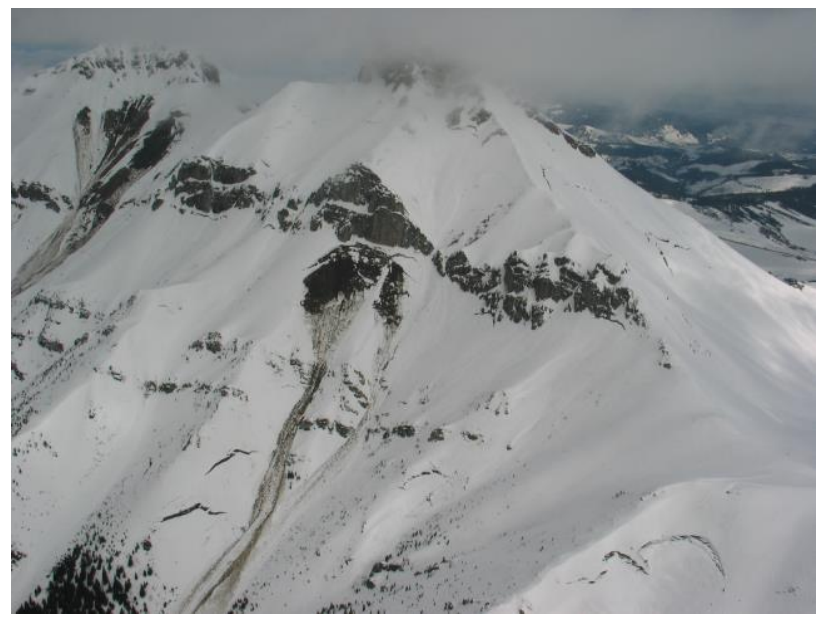

Figure 2: Avalanches in the area of the Belianske Tatry, photograph taken on April 1, 2009. Source: Slovakian Avalanche Prevention Center.

Several huts, bridges, two automatic weather stations and $1,000,000 \mathrm{~m}^{2}$ of forest were destroyed. Some of the avalanches were mapped using field based GPS instruments by staff of the Slovakian Avalanche Prevention Center (APC). Yet, much of the affected area is remote and knowing exactly where avalanches had released was a challenge for the authorities.

Very High Resolution (VHR) satellite imagery was fast recognized as potentially being an important source of information to map avalanches which had released in more remote areas. Therefore, the APC acquired WorldView-1 imagery from April 2, 2009, covering parts of the Tatra

* Corresponding author 
Mountains, in order to detect and map avalanches in regions that were inaccessible for the field teams.

\subsection{Avalanche mapping techniques}

1.2.1 Traditional methods: With few exceptions in densely studied areas (e.g., around avalanche research stations), snow avalanches are, in general, relatively poorly mapped. This is commonly due to the remote location of their occurrence. Often avalanches are only reported if they caused fatalities, led to an obstruction to public infrastructure, damage to personal property, or are witnessed and reported by local observers. However, decisions regarding, e.g., the closure of roads and the setting of warning levels, rely on information derived from knowledge of historic events in combination with meteorological data of the recent past and expected future.

The general practiced routine for mapping snow avalanches relies on two main techniques: a) the first technique involves a field mission to map the extent and location of avalanche startzones and runout-zones by hand, by amateur photographs, or with a GPS device. Problems related to this method are poor accessibility of the terrain due to avalanche danger, that only small areas can be surveyed, and that surveys only can be conducted in good weather. b) The second commonly used technique for mapping snow avalanches is the visual analysis and digitising of aerial photographs or optical remote-sensing imagery (Scott, 2009). Both methods require expert involvement and visual identification of an occurred snow avalanche.

Identified and mapped avalanches are usually used to nourish avalanche data bases, also known as avalanche cadastres. A small section of an avalanche map based on data from the Slovakian avalanche cadastre (accessible online at http://mapy.hiking.sk/) is visualised in Figure 3. In this map, the length of the avalanche paths is the longest ever recorded in a given avalanche path.

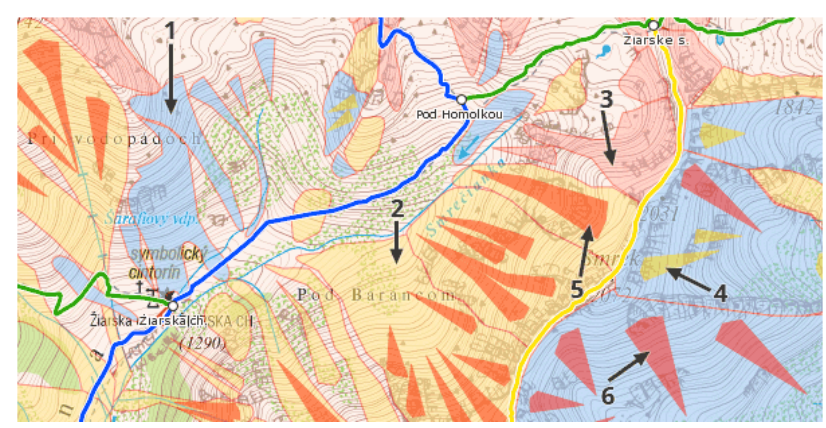

Figure 3: Slovakian avalanche map, example from the Žiarska valley. Blue colour $=$ slopes with an infrequent occurrence of avalanches; yellow $=$ slopes with frequent occurrence of avalanches; red = slopes with very frequent occurrence of avalanches. Triangular shapes in orange, red and yellow within a given avalanche frequency zone mark avalanche paths with a higher frequency than the respective zone they are located in would indicate. (Map source: Copyright $\odot$ HZS, hiking.sk, SHOcart)

Such maps are used to estimate regional susceptibility, to perform risk assessments and, eventually, to design hazards maps which directly link to policy making, i.e., to land use planning and land use regulations. More frequent information on avalanche occurrences provides decision makers with knowledge of the frequency of avalanches as well as details regarding the size and extent of such events. It becomes, therewith, evident that the more and better observations that are available, the more reliable avalanche databases and avalanche maps can become.

1.2.2 Applying VHR optical imagery: The ability to automatically identify snow avalanches using VHR optical imagery greatly assists in the development of such accurate, spatially widespread, detailed maps and databases of areas historically prone to avalanches.

Recent developments in the field of imaging sensors and data processing techniques in the last two decades have resulted in the use of remotely sensed data for various and diverse applications for hazard mapping. Advancements in data collection techniques are producing imagery at previously unprecedented and unimaginable spatial, spectral, radiometric and temporal resolution. The advantages of using remotely sensed data vary by topic, but generally include safer evaluation of unstable and/or inaccessible regions, high spatial resolution, spatially continuous and multi-temporal mapping capabilities (change detection) and automated processing possibilities. Of course, as with every method, there are also disadvantages involved with the use of remotely sensed data. These are generally in relation to the lack of ground truth data available during an analysis and to data acquisition costs.

Recent publications in the literature on the use of optical remote sensing for hazard applications include, among others: landslide and rockfall evaluation (e.g., Mantovani et al., 1996; Roessner et al., 2005; Miller et al., 2012;), flood mapping and modelling (e.g., Townsend and Walsh, 1998; Sanyal and Lu, 2004), glacier- and permafrost related hazard assessements (e.g., Kääb et al., 2005) and avalanche detection (Bühler et al., 2009; Lato et al., 2012). An extensive list of various satellite and airborne sensors with sufficient resolution for such analyses is given in, for example, Lato et al. (2012).

\section{DATA AND RESULTS}

The Slovakian Avalanche Prevention Center (APC) acquired WorldView-1 imagery from April 2, 2009, which covered large parts of the Tatra Mountains. While the eastern part of the imagery (Figure 4) was totally cloud-free, featuring a stunning quality, the western part was largely cloud-covered, thus, hampering its further use for avalanche detection, both for manual and automatic detection.

\subsection{Algorithm training}

The algorithm that we applied was originally designed to perform on data from a multi-band, 12-bit opto-electronic pushbroom scanner by Leica (ADS40-SH52; cf., Bühler et al., 2009) and on VHR optical imagery from the QuickBird satellite (cf., Lato et al., 2012). The algorithm was subsequently trained further on WorldView-1 imagery from Norway (not discussed here) and using the south-eastern third of the Slovakian imagery (marked with a blue rectangle in Figure 4). 


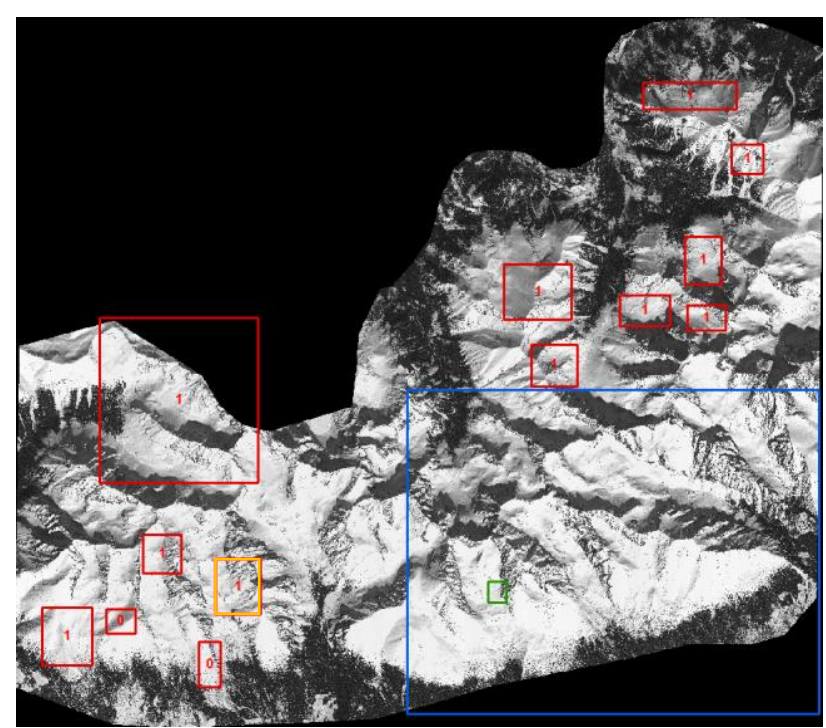

Figure 4: Eastern part of the WorldView-1 imagery from April 2, 2009. Blue rectangle $=$ algorithm training area; green rectangle $=$ location of example shown in Figure 5; red rectangles $=$ randomly selected test areas for validation $(0=$ no avalanches present; $1=$ avalanches present); orange rectangle $=$ location of example shown in Figures 7, 8. (Satellite image:

Copyright (C) DigitalGlobe/WorldView-1; courtesy of Slovakian Avalanche Prevention Center).

Even though the results of the first training runs looked seemingly satisfactory when just analysing a small portion of the imagery, the algorithm did not perform satisfactory on larger subsets of the data. On the one hand side the mapped avalanche debris was punctuated by small holes (i.e., errors of omission); at the same time many areas, especially wind-blown areas and rock outcrops, were falsely classified as avalanche debris (i.e., errors of commission).

Analysing the Slovakian imagery more closely, we observed a distinct "rake" pattern in many lower-lying areas of the imagery. We found that the rake pattern is more pronounced at lower altitudes, with the $1700 \mathrm{~m}$ a.s.l. contour line approximately delineating the height below which the problem starts occurring. The features showed to be the result of melting processes, caused either by a rain-on-snow event or even just by increasing air temperatures. Therefore we had to adapt the algorithm in order to eliminate these features prior to the actual avalanche debris mapping.

Figure 5 shows an example of the performance of the adapted algorithm enabling the differentiation between the "rake" pattern snow and avalanche debris.

For the time being, refinement of the algorithm based on training data is completed. Figure 6 shows an overview of the processing results for the entire training area.

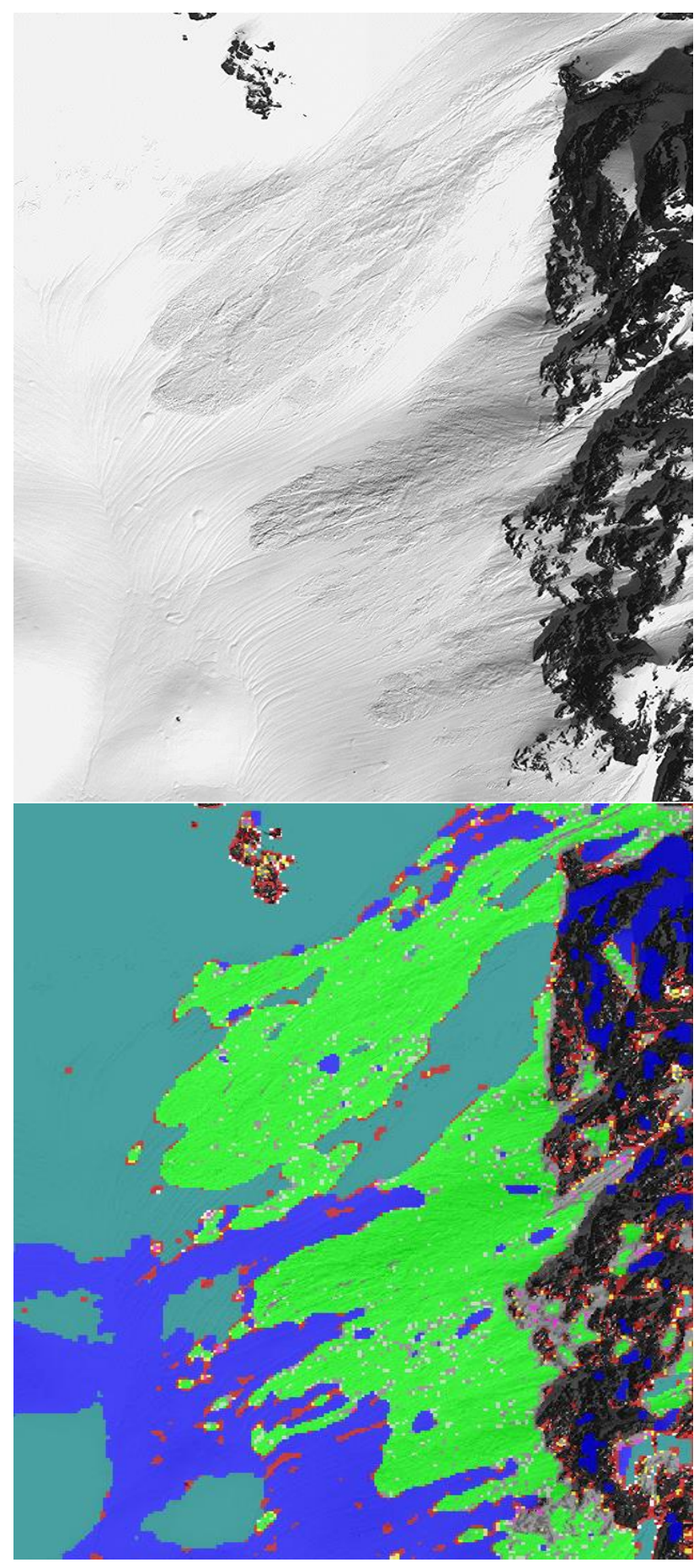

Figure 5: Classification result with the refined algorithm trained to differentiate the "rake" pattern from avalanche snow; the shown training section corresponds to the green rectangle in Figure 4. Top) raw image; bottom) automatic classification: green $=$ avalanche debris; turquoise $=$ glare and non-avalanche snow without rake pattern; blue = rake pattern; red = rock outcrops (Satellite image: Copyright $(\subset$

DigitalGlobe/WorldView-1). 


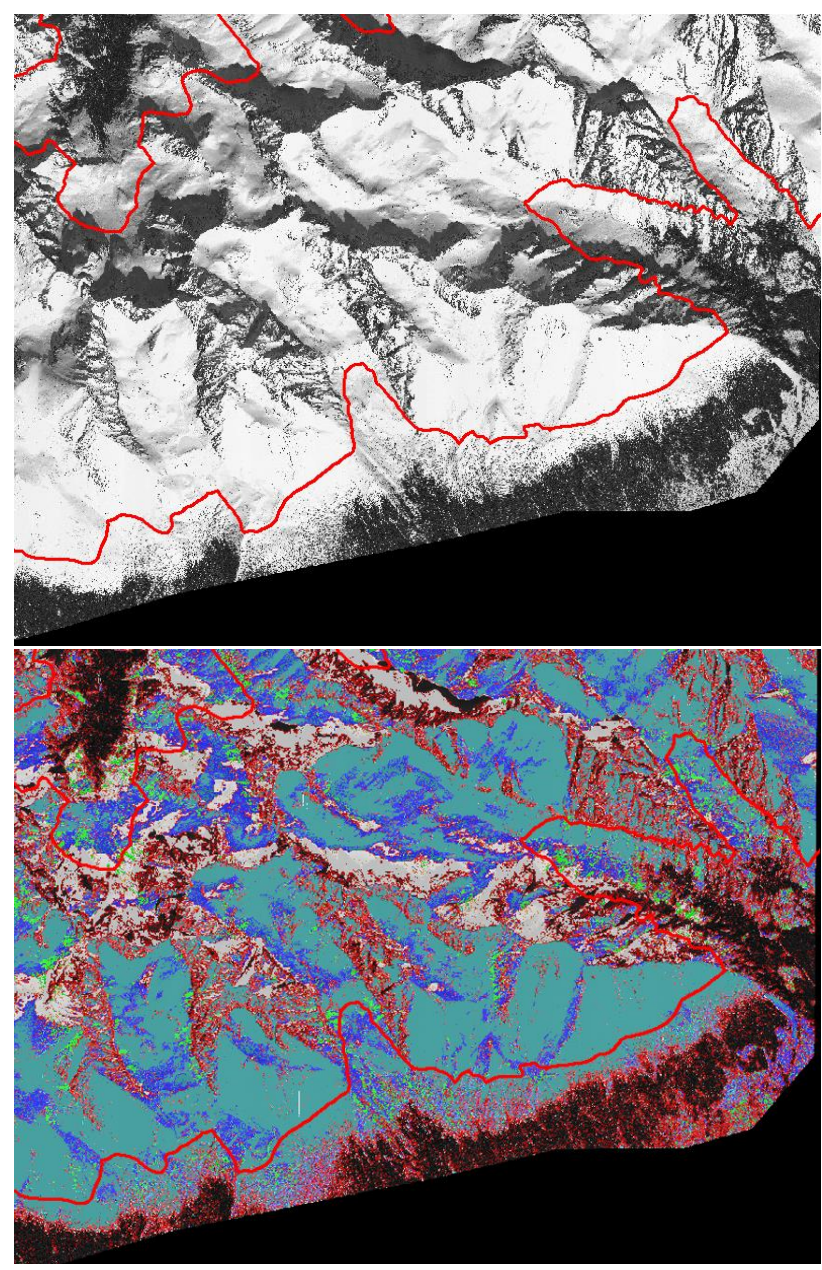

Figure 6: Automatic avalanche detection for the entire

Slovakian training area. Top) raw image; bottom) green $=$ avalanche debris; turquoise $=$ glare and non-avalanche snow without rake pattern; blue $=$ rake pattern; red $=$ rock outcrops and forested areas; red line $=1700 \mathrm{~m}$ a.s.l. contour line which approximately delineates the height below which the "rake pattern" problem starts occurring in this data set. (Satellite image: Copyright (c) DigitalGlobe/WorldView-1).

\subsection{Algorithm testing}

Currently, we are testing and validating the trained algorithm in randomly selected test areas of the Slovakian data set (red rectangles in Figure 4). In order to quantitatively assess the performance of the algorithm, all avalanches in the test areas were visually identified and manually digitized by an avalanche expert. An example of the manually digitized avalanches is shown in Figure $7 \mathrm{~b}$.

A qualitative comparison between expert mapping and automatic classification by the algorithm seems to indicate that the algorithm struggles in areas with strong pixel saturation. This finding is not surprising as such, as this has already been reported by both Bühler et al. (2009) and Lato et al. (2012). However, oversaturation seems to be more of an issue in WorldView-1/2 imagery than in previously explored data sets such as QuickBird imagery and airborne pushbroom scanner data. Indeed, of recent WorldView-1 acquisitions over Norwegian terrain (not further discussed here), oversaturation was an issue in three out of four acquired data sets and one recently acquired WorldView-2 data set was not analysable at all due to oversaturation over large and critical areas of the imagery.

It also has to be noted that the manual avalanche mapping was demanding, especially the delineation of the release areas of the point release avalanches (which account for a large proportion of the avalanches in the eastern part of the Slovakian imagery) and the mapping in shadow areas posed challenges. So in principle, neither the results by the human observer nor those by the algorithm give the entire "true" picture. But for the sake of a first evaluation of the algorithm performance, the human mapping was considered as representing the "true" situation.

The quantitative comparison of the algorithm performance with respect to the expert mapping shows a good overall performance with comparable rates of errors of omission and errors of commission if one takes the expert mapping as the "true" situation (Table 1; Figure 8). However, the processed test area is small and the overall algorithm performance on the WorldView-1 imagery can first be assessed when all the selected test areas have been processed.

Table 1. Accuracy (in percent) of the avalanche classification algorithm versus the manual digitizing method in one of the randomly selected test areas (orange rectangle in Figure 4).

\begin{tabular}{|l|c|}
\hline Overall correct detection rate & 84.2 \\
- No avalanches (transparent areas in Fig. 8) & 69.4 \\
- Avalanches (blue areas in Fig. 8) & 14.7 \\
Omission error (red areas in Fig. 8) & 7.3 \\
Commission error (yellow areas in Fig. 8) & 8.6 \\
\hline
\end{tabular}

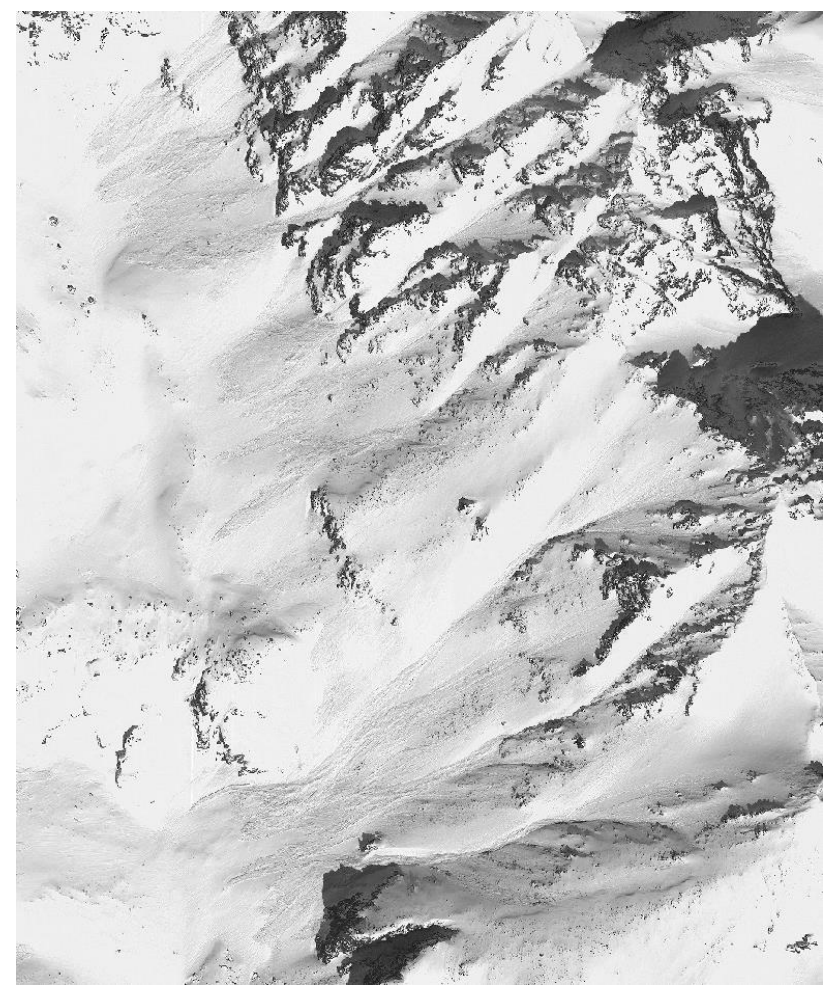

Figure 7a: Qualitative comparison between expert mapping and algorithm performance: Raw image. (Satellite image: Copyright (C) DigitalGlobe/WorldView-1) 


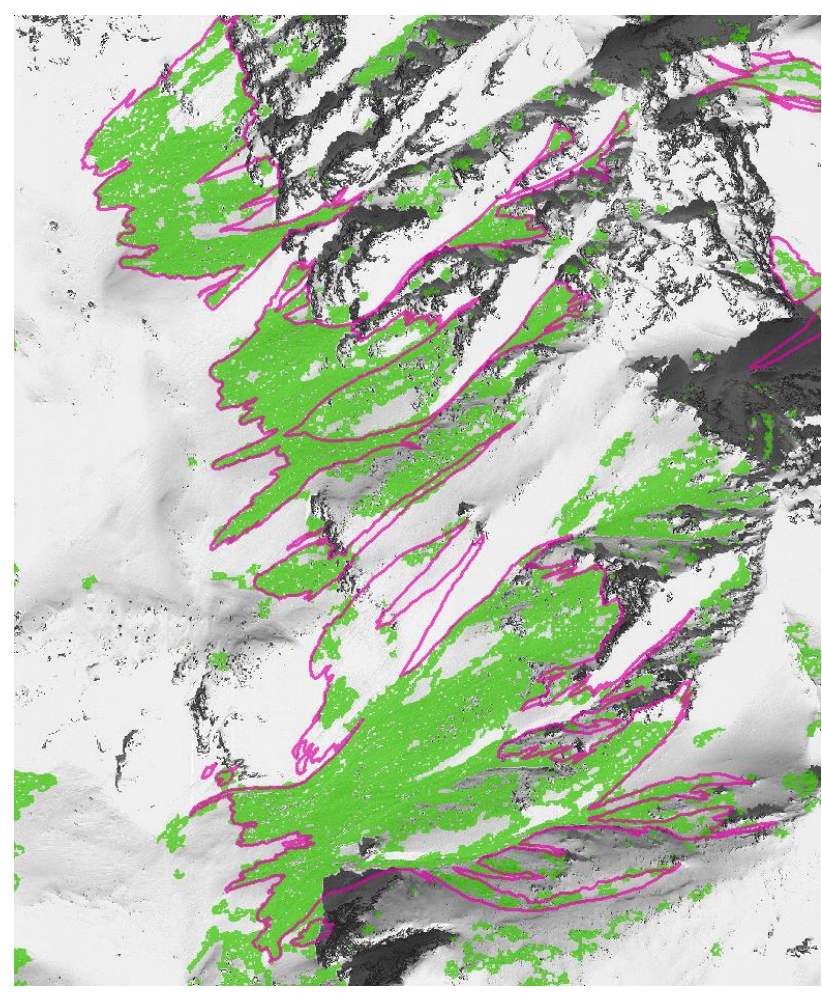

Figure 7b: Qualitative comparison between expert mapping and algorithm performance: manually digitized avalanche outlines

(in pink) superimposed on the automatically classified avalanches (in green). (Satellite image: Copyright $($ ) DigitalGlobe/WorldView-1)

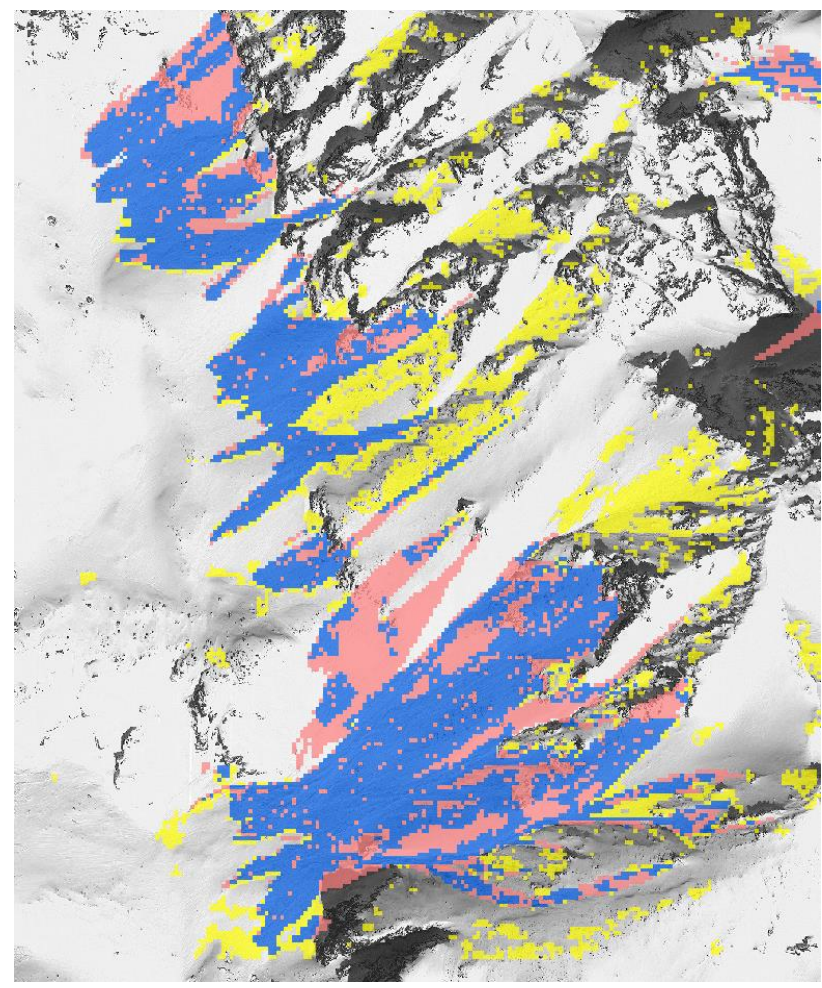

Figure 8: Quantitative comparison between expert mapping and algorithm performance. Blue = mapped as avalanche snow by both methods; red $=$ only mapped as avalanche snow by manual method; yellow = only mapped as avalanche snow by algorithm.

(Satellite image: Copyright $($ ) DigitalGlobe/WorldView-1).

\section{CONCLUSIONS}

We presented results of avalanche debris detection by an automatic detection algorithm implemented within eCognition.

The method described and illustrated above is flexible and easily adaptable to different sensors and image quality, however it requires further testing and validation before, e.g., implementation in an operational setting is possible.

\section{ACKNOWLEDGEMENTS}

This contribution was partly funded by the ESA PRODEX project ASAM ("Towards an automated snow property and avalanche mapping system"; contract no. 4000107724). The satellite image from the Tatra Mountains was obtained with the support of the Slovakian Ministry of Interior, Department of Scientific and Technological Development. Kristine Ekseth (NGI) is acknowledged for her help during an early phase of the algorithm training and Galina Ragulina (NGI) for her meticulous manual mapping of the numerous avalanches in the presented data set.

\section{REFERENCES}

Bühler, Y., Hüni, A., Christen, M., Meister, R., Kellenberger, T. 2009. Automated detection and mapping of avalanche deposits using airborne optical remote sensing data. Cold Reg. Sci. Technol., 57, 99-106.

Kääb, A., Huggel, C., Fischer, L., Guex, S., Paul, F., Roer, I., Salzmann, N., Schlaefli, S., Schmutz, K., Schneider, D., Strozzi, T., Weidmann, Y. 2005. Remote sensing of glacier- and permafrost-related hazards in high mountains: an overview. Nat. Hazards Earth Syst. Sci., 5, 527-554, doi:10.5194/nhess-5-5272005.

Lato, M., Frauenfelder, R., Bühler, Y. 2012. Automated detection of snow avalanche deposits: segmentation and classification of optical remote sensing imagery. Nat. Haz. And Earth. Syst. Sci., 12, 2893-2906. doi:10.5194/nhess-12-28932012.

Mantovani, R., Soeters, R., van Western, C. J. 1996. Remote sensing techniques for landslide studies and hazard zonation in Europe. Geomorphology, 15, 213-225.

Miller, P.E., Mills, J.P., Barr, S.L., Birkinshaw, S.J., Hardy, A.J., Parkin, G., Hall, S.J. 2012. A Remote Sensing Approach for Landslide Hazard Assessment on Engineered Slopes. Geoscience and Remote Sensing, IEEE Transactions, 50(4), pp. 1048, 1056, doi: 10.1109/TGRS.2011.2165547.

Roessner, R., Wetzel, H.-U., Kaufmann, H., Sarnagoev, A. 2005. Potential of Satellite Remote Sensing and GIS for Landslide Hazard Assessment in Southern Kyrgyzstan (Central Asia). Natural Hazards, 35(3), 395-416.

Sanyal, J., Lu, X.X. 2004. Application of Remote Sensing in Flood Management with Special Reference to Monsoon Asia: A Review. Natural Hazards, 33(2), pp. 283-301.

Townsend, P.A., Walsh, S.J. 1998. Modeling floodplain inundation using an integrated GIS with radar and optical remote sensing. Geomorphology, 21(3-4), pp. 295-312. 